\title{
LEARNER INTERACTIONS AND BEHAVIORAL PATTERNS IN ENTERPRISE MOOCS
}

\author{
Marc Egloffstein ${ }^{1}$, Muhittin Şahin ${ }^{2}$, Max Bothe $^{3}$, Tobias Rohloff ${ }^{3}$, Nathanael Schenk ${ }^{4}$, \\ Florian Schwerer ${ }^{4}$ and Dirk Ifenthaler ${ }^{5}$ \\ ${ }^{1}$ University of Mannheim, Germany \\ ${ }^{2}$ Ege University, Turkey and University of Mannheim, Germany \\ ${ }^{3}$ Hasso Plattner Institute, Potsdam, Germany \\ ${ }^{4}$ SAP SE, Walldorf, Germany \\ ${ }^{5}$ University of Mannheim, Germany and Curtin University, Australia
}

\begin{abstract}
This short paper investigates learner behavior in Enterprise MOOCs with the help of interaction patterns. By means of lag sequential analysis, data from 13 openSAP MOOCs from the topic areas business, design, and technology with a total number of $N=72,668$ active learners have been analyzed. Starting from consistent high-level behavioral patterns, a deeper analysis on the interaction level revealed variations between the course topic areas: Behavioral patterns in technology courses differ from business and design courses. Drawing upon these results, implications for future research are mapped out.
\end{abstract}

\section{KEYWORDS}

Enterprise MOOC, openSAP, Sequential Analysis, Behavioral Patterns, Learning Analytics

\section{INTRODUCTION}

MOOCs have become a viable alternative for corporate training and professional development (Egloffstein \& Ifenthaler, 2017). A notable example of this is openSAP, an open learning platform related to the Tech/IT-sector. While many companies do not seize the full potential of MOOCs for training and development (Condé \& Cisel, 2019) or lack adequate support (Hamori, 2019), openSAP implements so-called Enterprise MOOCs (Schwerer \& Egloffstein, 2016) to convey knowledge about new technologies and business topics within the organization as well as to external stakeholders throughout the 'SAP universe' (Renz et al., 2019). Against the background of the common criticism of MOOCs in terms of instructional quality (Egloffstein et al., 2019) or completion rates (Reich \& Ruipérez-Valiente, 2019), openSAP seeks to optimize its offering and to constantly improve the learning experience based on learning analytics (Khalil \& Ebner, 2016).

This paper reports on the results of an initial study conducted as part of an academia-industry R\&D partnership around openSAP. Focusing on learner behavior in different Enterprise MOOCs, the project aims to develop data-driven recommendations for learning design (Ifenthaler, 2017) and course facilitation. Following on from previous research (Rohloff et al., 2020), the study seeks to (a) identify typical behavioral patterns in openSAP Enterprise MOOCs and (b) determine whether such patterns differ between courses from different topic areas. This work-in-progress report extends existing high-level findings (Şahin et al., 2021) by analyzing learner behavior at the more granular level of system interactions.

\section{METHOD}

\subsection{Sequential Analysis of Learning Behavior}

As a well-established method of inferential statistics (Wald, 1973), sequential analysis can be employed for investigating behavior of learners in online learning systems (Şahin et al., 2020). It is a suitable approach when 
investigating behavior within an ongoing interaction (Bakeman \& Gottman, 1997) and has been applied to various MOOC settings (e.g. Liu et al., 2021). Sequential relationships of observations and events with each other are also considered in sequential analysis (Bakeman \& Gottman, 1997). Log-linear models, lag sequential methods, z-scores, and sequential pattern mining can be used to determine sequential patterns. In order to identify typical learning behaviors, transition probabilities are used to identify significant patterns (Bakeman \& Gottman, 1997). The stochastic models provide the mathematical basis for precisely computing learning-dependent changes in online learning environments such as MOOCs. The Lag Sequential Analysis (LSA) process for this project consists of five distinctive steps: (1) develop event sequences, (2) map out transitional frequency matrices, (3) derive the transitional probability matrix, (4) calculate $\mathrm{z}$-scores and carry out a test of significance, and (5) create a state transition diagram.

\subsection{Sample, Data Collection, and Procedure}

User events from 13 openSAP courses from the topic areas Business, Design and Technology have been analyzed with regard to patterns in learner behavior. The courses in the sample show variations in terms of length, effort, and design parameters like assessment configuration or additional instructional design elements (e.g., reflection prompts or coding exercises). The data used to conduct LSA consists of learners' interactions with the digital learning environment on the basis of traceable system states and events. In a preceding step of data preparation, the event data generated by platform interactions was coded based on the individuals. A total of 10,454,430 activities of $\mathrm{N}=72,668$ professional and/or lifelong learners were analyzed. The sample reflects the characteristics of the overall population of openSAP learners, about two-thirds of whom are between 25 and 40 years old.

Following the overall structure of the openSAP MOOC platform, the learner events within a course were assigned to four main categories on a global level: learning (L), discussion (D), progress (P), and announcement (A). To gain deeper insights, we examined learners' sequential behavior patterns on the more granular level of system interactions. These interactions consist of 20 system events such as submitting assignments, downloading presentations, submitting surveys, visiting textual instructions, visiting videos, playing videos from category (L), posting comments, posting replies for category $(\mathrm{D})$, visiting progress in category $(\mathrm{P})$, and visit announcements in category (A).

In the first step of LSA, event sequences were created for each learner based on the interactions with the learning platform. An example of such a event sequence would be: LLLLDDLLLPDAALLLL. In the second step, transitional frequency matrices were created. Then, the transitional probability matrix was mapped out. Transitional probability is a conditional probability; events occur in different times and 'lag' is used to express these time differences (Şahin et al., 2020). In order to test the statistical significance of the transitions, z-scores were calculated, together with a Bonferroni adjustment to determine the $\mathrm{z}$-score threshold. In the last step, a state transition diagram was generated for displaying the results.

\section{RESULTS}

\subsection{Transitions Between Top Level Categories}

Over all 13 courses in the sample, significant transitions between the four main categories could be traced. The respective state transition diagram for the high-level interactions is shown in Figure 1.

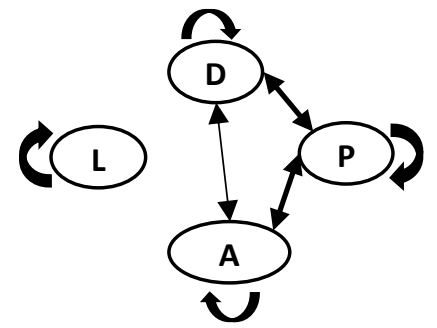

Figure 1. State Transition Diagram for the Overall Sample 
The state transition diagram shows significant transitions between all the main categories except for the learning category. Looking at high-level interactions, the biggest category in terms of events captured is rather isolated.

With regard to the second research question, LSA was carried for each 'course bucket' (i.e., set of courses from one topic area) separately. As the learning category, again, remains isolated from the others, the data show a consistent pattern on this high level of analysis. Apart from that, behavioral patterns are similar but with some minor differences. For example, learners interact within the discussion category and then interact with the progress.

\subsection{Transitions between Interaction Level Categories}

There are twenty interaction categories and numerous transitions on the interaction level. An excerpt of the transition table for two interaction categories is presented in Table 1. Detailed information about these system interactions can be found in the appendix.

Table 1. Transitions on the Interaction Level

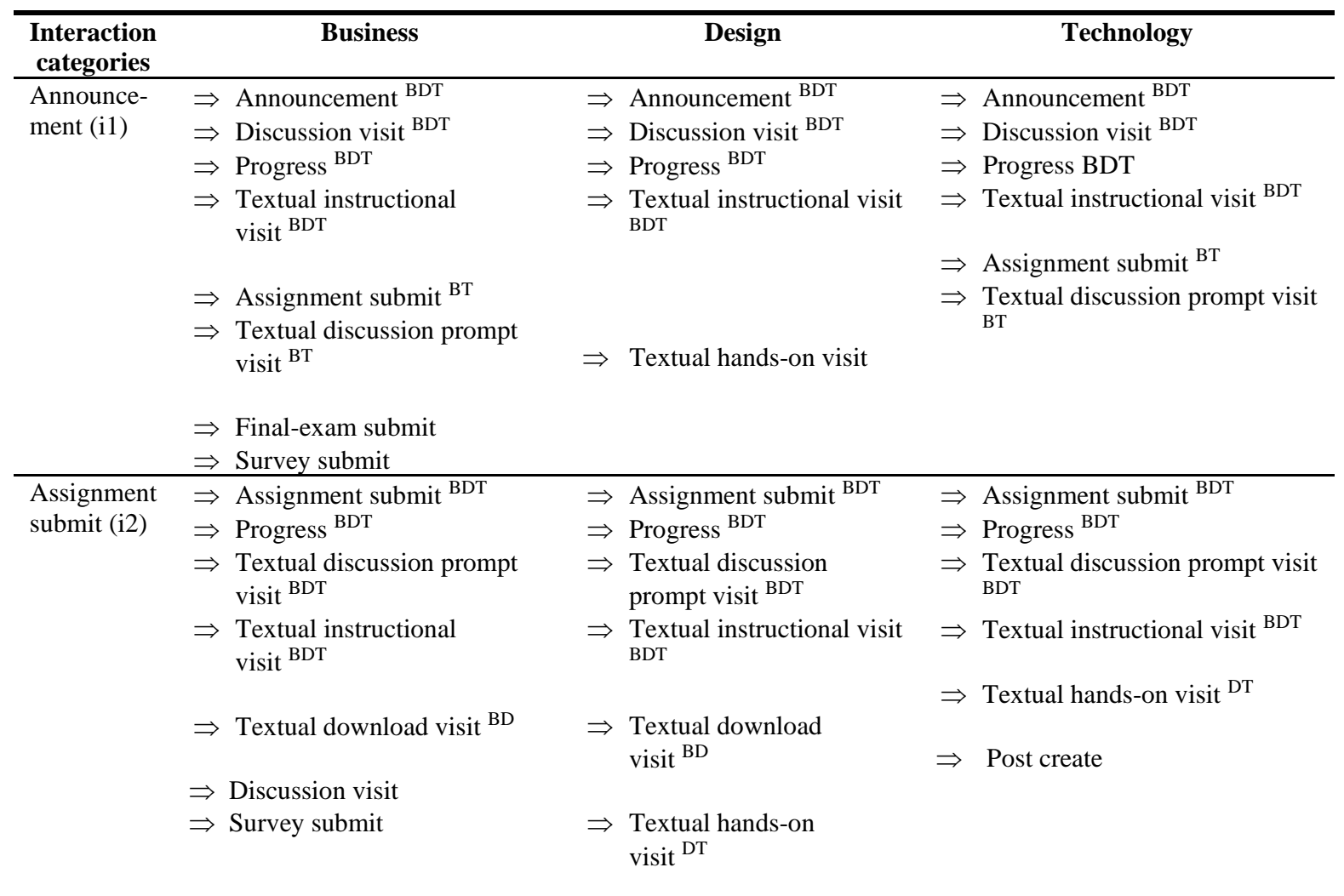

Note. $\quad$ BDT joint transitions for Business, Design, and Technology; ${ }^{\mathrm{BD}}$ joint transitions for Business and Design; ${ }^{\text {BT }}$ joint transitions for Business and Technology; DT joint transitions for Design and Technology

Results show that learners interacted with the announcements, discussions, progress, and textual instructions after visiting announcements in the courses from all three topic areas. Learners interacted with assignments and textual discussion prompts areas after visiting announcements in the Business and Technology courses. In addition to these, learners interacted with final-exams and surveys after visiting announcements in the Business courses. Looking at the assignment category, results show that learners interact with assignments, progress, textual discussion prompts, and textual instructions after visiting assignments in all three topic areas. Learners interacted with textual downloads after visiting assignments in the Business and Design courses. Learners visited textual hands-ons after visiting assignments in the Design and Technology courses. 
Looking at the results of the LSA from a holistic perspective, both similarities and differences in students' sequential interaction preferences according to the course topic area become evident. Interactions of students in the Business and Technology areas seem rather similar.

From a closer perspective, sequential analysis shows that learners interact first with the assignments and then with the progress. Or, on the contrary, learners interact first with the progress and then with assignments. This result can be interpreted as learners submitting their task and then controlling their process/task or vice versa. Submissions of self-tests tend to induce video visits. This could be interpreted an indicator for a demand of additional knowledge about the respective topic. When learners download the video they also tend to download the audio and presentation. Learners can find information about the learning content and course elements when they visit the textual interactions. After visiting the textual instructions, learners interact with the announcements, submit surveys, and visit textual instructional prompts, textual downloads, textual instructions, and videos. This allows the interpretation that when learners discover the course details, they tend to visit the course elements and interact with these.

\section{DISCUSSION}

This work-in-progress study reported typical behavioral patterns in openSAP Enterprise MOOCs and possible variations between courses from different topic areas on the granular level of system interactions. Findings indicate that (1) there are consistent patterns, and (2) many characteristics of those patterns also apply when a differential perspective is adopted with respect to the topic areas. Among the top level categories, the learning category, which contains the majority of system interactions, remains isolated from the other categories. This might be due to a clear learner focus on working through the content and towards the assignments, while the announcement, progress, and discussion categories are more likely to be addressed at the beginning or the ending of a learning session. Moreover, announcements are also communicated via additional channels (e.g., via e-mail), and the learner progress is evident in the learning area, too. So if there is a need to better connect learning activities to collaborative (e.g., discussions) or meta-cognitive (e.g., announcements or progress visits) activities, cannot be decided at this stage yet.

The detailed analysis on the interaction level focused on the learning environment and its linear structure. The interactions are presented to the learners respectively, for example textual instructional visit, video visit, self-test, video visit, etc., textual download visit, and assignment submit. But when we examine the sequential transitions, learners do not prefer to interact with the remaining learning elements. Generally, one would expect learners to interact with a video and then with a self-test (Li et al., 2015). However, this is not observed in the interactions. Findings show that learners play the video without subsequent significant transitions to the other interactions afterwards. Thus, a more detailed analysis is needed. For example, video metrics such as play, pause, etc. could be taken into consideration here ( $\mathrm{Li}$ et al, 2015).

To sum up the findings, we can conclude that if there is an access link in the pages, learners will interact with these materials sequentially. When we look at the results of LSA, both similarities and differences in students' sequential interaction preferences according to the topic areas become evident. Apparently, the interactions of students in courses from the Business and the Technology area are more similar. Within the scope of this research, LSA was conducted based on the system events. In addition, other metrics such as time spent could be included (Boroujeni \& Dillenbourg, 2019), allowing for the discovery of more in-depth patterns and a deeper understanding of the learning process (Ifenthaler et al., 2018; Knight et al., 2017). After all, we expect to gain deeper insights into (successful) online-learning behavior in openSAP by combining LSA results with progress and performance data in the following steps of the research project.

\section{REFERENCES}

Bakeman, R., \& Gottman, J. (1997). Observing interaction: An introduction to sequential analysis (2nd ed.). Cambridge University press.

Boroujeni, M., \& Dillenbourg, P. (2019). Discovery and temporal analysis of MOOC study patterns. Journal of Learning Analytics, 6(1), 16-33. https://doi.org/10.18608/jla.2019.61.2 
Condé, J., \& Cisel, M. (2019). On the Use of MOOCs in Companies: A Panorama of Current Practices. In M. Calise, C. Delgado Kloos, J. Reich, J. Ruiperez-Valiente \& M. Wirsing (Eds.), Digital Education: At the MOOC Crossroads Where the Interests of Academia and Business Converge. LNCS Vol. 11475 (pp. 37-46). Springer. https://doi.org/10.1007/978-3-030-19875-6_5

Egloffstein, M., \& Ifenthaler, D. (2017). Employee perspectives on MOOCs for workplace learning. TechTrends, 61(1), 65-70. https://doi.org/10.1007/s11528-016-0127-3

Egloffstein, M., Koegler, K., \& Ifenthaler, D. (2019). Instructional quality of business MOOCs: Indicators and initial findings. Online Learning, 23(4), 85-105. https://doi.org/10.24059/olj.v23i4.2091

Hamori, M. (2019). MOOCs at work: what induces employer support for them? The International Journal of Human Resource Management. Advance online publication. https://doi.org/10.1080/09585192.2019.1616593

Ifenthaler, D. (2017). Learning analytics design. In L. Lin \& J. M. Spector (Eds.), The sciences of learning and instructional design. Constructive articulation between communities (pp. 202-211). Routledge. https://doi.org/10.4324/9781315684444-13

Ifenthaler, D., Gibson, D. C., \& Dobozy, E. (2018). Informing learning design through analytics: Applying network graph analysis. Australasian Journal of Educational Technology, 34(2), 117-132. https://doi.org/10.14742/ajet.3767

Khalil, M., \& Ebner, M. (2016). When Learning Analytics Meets MOOCs - a Review on iMooX Case Studies. In G. Fahrnberger, G. Eichler \& C. Erfurth (Eds.), Innovations for Community Services. 16th International Conference I4CS (pp. 3-19). Springer. https://doi.org/10.1007/978-3-319-49466-1_1

Knight, S., Wise, A., \& Chen, B. (2017). Time for Change: Why Learning Analytics Needs Temporal Analysis. Journal of Learning Analytics, 4(3), 7-17. https://doi.org/10.18608/jla.2017.43.2

Li, N., Kidziński, Ł., Jermann, P., \& Dillenbourg, P. (2015). MOOC video interaction patterns: What do they tell us? In G. Conole, T. Klobučar, C. Rensing, J. Konert \& É. Lavoué (Eds.), Design for teaching and learning in a networked world. LNCS Vol. 9307 (pp. 197-210). Springer. https://doi.org/10.1007/978-3-319-24258-3_15

Liu, B., Wu, Y., Xing, W., Cheng, G., \& Guo, S. (2021). Exploring behavioural differences between certificate achievers and explorers in MOOCs. Asia Pacific Journal of Education. Advance online publication. https://doi.org/10.1080/02188791.2020.1868974

Reich, J., \& Ruipérez-Valiente, J. A. (2019). The MOOC Pivot. Science 363(6423), 130-131. https://doi.org/10.1126/science.aav7958

Renz, J., Meinel, C., \& Link, C. (2019). openSAP: Why Are Enterprise MOOCs Working? International Journal of Advanced Corporate Learning, 12(3), 59-69. https://doi.org/10.3991/ijac.v12i3.11262

Rohloff, T., Schwerer, F., Schenk, N., \& Meinel, C. (2020). openSAP: Learner behavior and activity in self-paced enterprise MOOCs. International Journal of Advanced Corporate Learning, 13(2), 30-40. https://doi.org/10.3991/ijac.v13i2.16531

Şahin, M., Keskin, S., \& Yurdugül H. (2020). Sequential Analysis of Online Learning Behaviors According to E-Learning Readiness. In P. Isaias, D. G. Sampson \& D. Ifenthaler (Eds.), Online Teaching and Learning in Higher Education (pp. 117-131). Springer. https://doi.org/10.1007/978-3-030-48190-2_7

Şahin, M., Egloffstein, M., Bothe, M., Rohloff, T., Schenk, N., Schwerer, F., \& Ifenthaler, D. (2021). Behavioral Patterns in Enterprise MOOCs at openSAP. In C. Meinel, T. Staubitz, S. Schweiger, C. Friedl, J. Kiers, M. Ebner, A. Lorenz, G. Ubachs, C. Mongenet, J. A. Ruipérez-Valiente \& M. Cortes Mendez (Eds.), EMOOCs 2021 (pp. 281-288). Universitätsverlag Potsdam. https://doi.org/10.25932/publishup-51030

Schwerer, F., \& Egloffstein, M. (2016). Participation and Achievement in Enterprise MOOCs for Professional Learning. In D. G. Sampson, J. M. Spector, D. Ifenthaler \& P. Isaias (Eds.), Proceedings of the 13th International Conference on Cognition and Exploratory Learning in the Digital Age (pp. 269-276). IADIS. https://eric.ed.gov/?id=ED571404

Wald, A. (1973). Sequential Analysis. Dover Publications. 


\section{APPENDIX}

Table 2. Detailed Findings for System Interactions

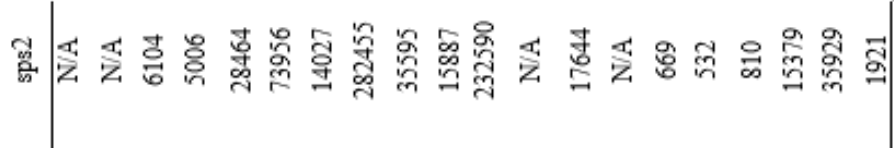

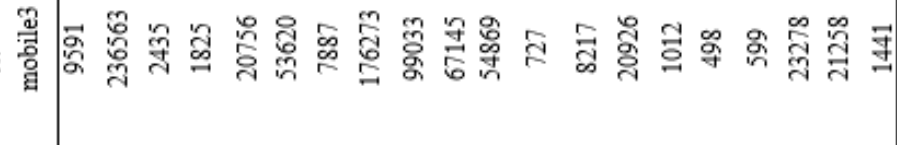

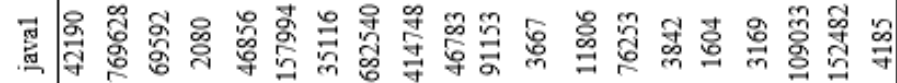

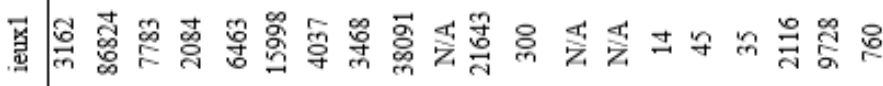

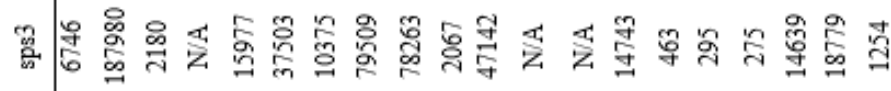

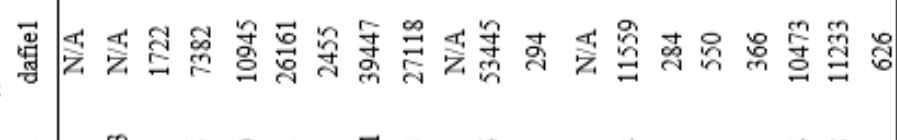

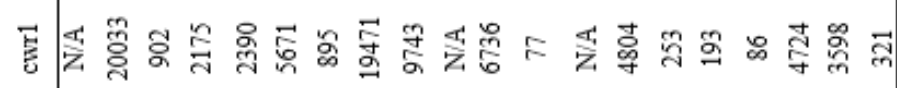

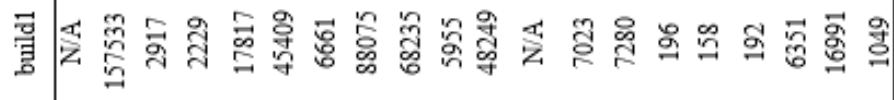

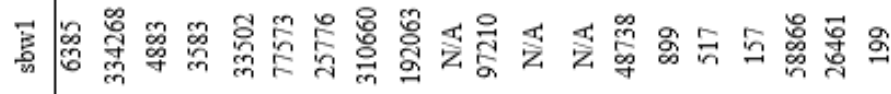

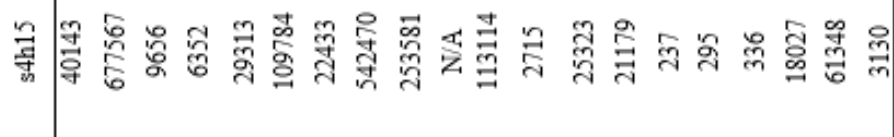

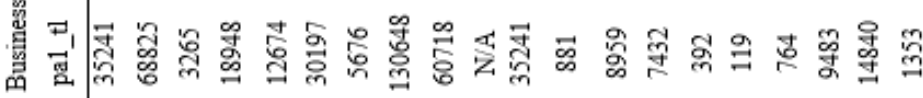

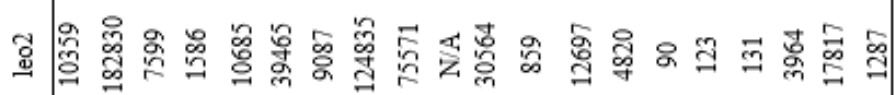

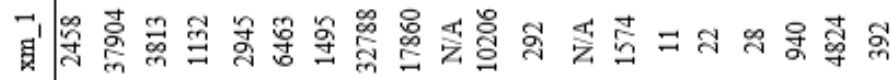

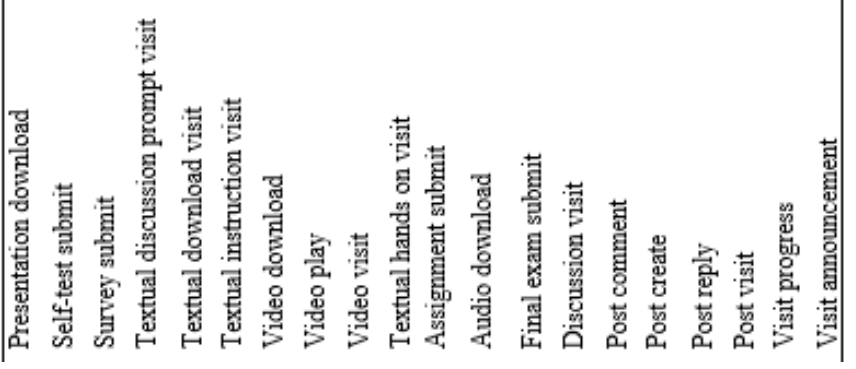

